\title{
The Recovery of Precious and Base Metals from E-Waste: A Review
}

\author{
Amil Memon \\ Final year M.Tech. Student, Environmental \\ Engineering, B.V.M.Engineering College, \\ Vallabh Vidyanagar, Gujarat, India
}

\author{
Prof. (Mrs) Reshma L. Patel \\ Associate Professor, Civil Engineering \\ Department, B.V.M.Engineering College \\ Vallabh Vidyanagar, Gujarat, India
}

\section{Dr. Jayeshkumar Pitroda}

Assistant Professor, Civil Engineering Department

B.V.M.Engineering College, Vallabh Vidyanagar, Gujarat, India

\begin{abstract}
Rapid Technological development induces increase of generation of used electric and electronic equipment waste, causing a serious threat to the environment. Waste printed circuit boards (WPCBs), as the main component of the waste, are significant source of base and precious metals especially copper and gold. Printed circuit boards (PCBs) are currently being dumped in landfills or incinerated which is causing a serious environmental harm in the form of toxic gases or leached hazardous compounds. To recover these metals from waste has always been a challenge. The paper here presents a detailed literature review on the components and the metal content of PCBs.
\end{abstract}

Keyword: Electronic Waste Management, Precious Metals, Printed Circuit Board (PCB), Recovery

\section{INTRODUCTION}

Old electronic equipment that has outlived their useful life is categorized as e- waste. As per various numbers published by various research agencies, about 20 to 50 million tons of e-waste are generated worldwide every year. E-waste comprises of more than $5 \%$ of all solid waste generated and the volume is expected to increase at a rate of $300 \%$ per annum in developing countries. On an average, in India, in case of mobile phones the useful life goes up to 2 years. In case of PCs, it may go up to 5 years. The life of this equipment is extended due to reasons such as upgrade, repair and reuse, donation to charity, etc.

Electrical and Electronic equipment contains Printed circuit boards (PCBs) that have metallic and non-metallic elements, alloys and compounds such as Copper, Aluminum, Gold, Silver, Palladium, Platinum, Nickel, Tin, Lead, Iron, Sulphur, Phosphorous, Arsenic etc. If discarded in the open, these metals can cause a severe environmental and health hazard.

Printed circuit boards (PCBs) are currently being dumped in landfills or incinerated which is causing a serious environmental harm in the form of toxic gases or leached hazardous compounds. PCBs contain high amounts of precious metals; about $20 \mathrm{wt} \%$ copper, $0.04 \mathrm{wt} \%$ gold, $0.15 \mathrm{wt} \%$ silver, and 0.01 wt $\%$ palladium. The extraction of these metals from PCBs is both profitable and environmentally worthwhile.

This study focuses on the extraction process of four metals; gold, silver, copper and palladium from PCBs of computers and mobile phones using the EMEW Electro winning Technology which results in metal purities of up to $99.99 \%$.

\section{Critical Literature RevieW}

The following are the previous research review based on recovery of precious and base metals from E-Waste.

Niederkom and Huzar et al (1984) are the pioneers who have worked on gold recovery from used electrical contactors. According to their estimate about 700 tonnes of gold must have been conspired 
in the manufacture of low voltage electrical contactors, which have become redundant over a period. Thus, gold becomes a candidate for recovery. Further, they have also demonstrated an average gold recovery rate of $95 \%$ from contactors by mechanical and chemical processing. [22]

Dunning B. W. Jr. et al (1986) have discussed the recovery of Precious Metals from Electronic Scrap and Solder used in Electronics Manufacture. [8]

Mellon and Matthews et al (1991) are the first to make organized attempts to estimate the computer waste disposal and recycling options. [20]

Boswell et al (1995) first published work on E-waste recycling who emphasizes the concept of demanufacturing design for disassembly in close loop for end of life cycle equipment. In Rio de Janeiro (3rd-14th June 1992) "Earth Summit" mention also has been made about the precautionary principles and sustainability of resources. Basel Convention, which came in to force in 1992, forbids industrialized nations from exporting their hazardous waste to developing countries without obtaining the permission in writing from the importing country and with the guarantee of treating the toxic substances in an environmental and eco-friendly manner. Canada, India and 168 other countries have ratified this treaty. [2]

Zhang and Forssberg et al (1998, 1999) have made series of attempts on Metal Recovery from Electronic Scrap using optimization studies on Corona discharge type equipment for separation of various fractions of Plastics, Copper and Aluminum etc. [30]

Dwelling et al (1999) study on house equipment statistics reveals, the average life (amount of PC time useful to its original owner) is 2-4 years and by the year 2005, a PC's first life is expected to decrease by another year, considering reuse and shortage options, the total lifespan (the period from manufacture to disposal) is estimated to at 3-4 years. He also states that the computer equipment includes desktop personal computers, notebooks, keyboards, printers and speakers. [9]

Nokia's Environmental Report (2000) According to which only $22 \%$ of the waste produced during 1997-98 was recycled.

Esko Nurmi (2000) who was responsible for waste management and recycling in Oulu facility of Nokia, says the volume of landfill waste could be significantly reduced during 1999 it is $58 \%$ during 2000 , and by 2001 the figure should rise to $60 \%$. [23]

Hesselbach et al $(1999,2001)$ have studied on combined strategy for recycling, based on Product and Process Oriented Quantitative Bench Marking and for close loop economy and economical efficiency. [10]

Jun Kim et al (2003) published a technical paper on "Selective Leaching of Valuable Metals such as $\mathrm{Cu}, \mathrm{Au}, \mathrm{Ag}, \mathrm{Pd}$ and $\mathrm{Pb}$ from Waste printed Circuit Boards". [7]

Jirang and Forssberg et al (2003) have conducted a study on Mechanical Recycling of E-waste using Magnetic, Conductivity, Density, Corona Electrostatic Separations and Jigging techniques. [13]

Chandra et al (2004) have discussed on Dissolution of gold in Thiosulphate solutions. Thiosulfate leaching appears to be the most promising alternative to cyanidation for the recovery of gold from ores. The paper presents a fundamental study on the gold oxidation half reaction in the solutions containing thiosulfate. [5]

Wolfarm et al (2005) writes on 'end of life treatment of second-generation electronic gadgets. Major greenhouse gas (GHG) emissions related to plastic waste recycling were evaluated with respect to three management alternatives: recycling of clean, single-type plastic, recycling of mixed/contaminated plastic, and use of plastic waste as fuel in industrial processes. It is an excellent report for complete treatment options for various waste plastic recycling. [26]

P. Gramatyka et al (2007) described the current status of waste electrical and electronic equipment recycling and disposal in Europe, and its impact on the environment, human health and the economy. Pyrometallurgical treatment in copper smelters is the common process for the recycling of electronic scrap. But the treatment of electronic scrap especially material with high contaminations oramount of plastic needs always a combination of different steps, i.e. mechanical, thermal and hydrometallurgical. [24] 
Balakrishnan Ramesh Babu et al (2007) addressed potential environmental problems that could stem from improper management of WEEE, also discussed about many countries and organizations drafted national legislation to improve the reuse, recycling and other forms of material recovery from WEEE to reduce the amount and types of materials disposed in landfills. Recycling of waste electric and electronic equipment is important not only to reduce the amount of waste requiring treatment, but also to promote the recovery of valuable materials. Described the generation, classification, strategies and the technologies for recovering materials and new scientific developments related to these activities. Also the e-waste recycling industry in India is also discussed. [1]

Central Pollution Control Board (CPCB) (2008) India, have brought out guidelines for environmentally sound management of E-waste, and Mercury Management in Fluorescent Lamp Sector. [4]

Jirang Cui et al (2008) depicted the state of the art in recovery of precious metals from electronic waste by pyrometallurgical processing, hydrometallurgical processing, and bio-Metallurgical processing. Pyrometallurgical processing as a traditional technology for recovery of precious metals from waste electronic equipment Hydrometallurgical processing techniques including cyanide leaching, halide leaching, thiourea leaching, and thiosulfate leaching of precious metals. Based on a critical comparison of various leaching methods from the points of view economic feasibility and environmental impact, it is concluded that leaching of gold by thiourea may be the most realistic substitute. Also, biotechnology has been one of the most promising technologies in metallurgical processing. [14]

Mathias Schluep, et al (2009) has discussed for the first time the social issues in the reuse of computers in developing countries like China, India and Peru. [19]

Brett H. Robinson et al (2009) gave an assessment of global production and environmental impact of E-waste. Report showed that most E-waste is disposed in landfills. Effective reprocessing technology, which recovers the valuable materials with minimal environmental impact, is expensive. [3]

Željko Kamberović et al (2009) proposed three hydrometallurgical processes for the recovery of copper and other precious metals from Waste Printed Circuit Boards (WPCBs) and also optimized it. The use of selective leachants for recovery of high purity metals (fluoroboric acid, ammoniaammonium salt solution), conventional leachants (sulphuric acid, chloride, cyanide) and eco-friendly leachants (formic acid, potassium persulphate). Suggested that selection of suitable hydrometallurgical process highly depend on leaching tests and techno-economical analysis [27]

UNEP (2010) in its report recycling from E-waste to resources indicates that electronic products in countries like China and India are set to rise sharply in the next 10 years. Further, global E-waste generation is growing by 40 million tons by 2020 . In India, over 56,300 tons of obsolete PCs and 47,000 tons of printers are estimated to be generated by 2020. [17]

Ruediger Kuehr et al (2010) paper on E-waste: "not your normal trash" has emphasized the need for toxic free solder by non-toxic substances, besides how the E-waste generation remains unaccounted. He further discusses on resource efficiency, partially burnt cables, circuit boards are deserted where cattle and people are moving. In order to extract precious materials or recycle parts for further use, this waste is finally processed in the majority of cases by crude backyard techniques such as applying acid baths to obtain gold or burning wires to remove insulation and get the copper. This emits dioxins and other pollutants and poses a danger to protect and their local environment. [25]

Ž. Kamberović et al (2010) carried out series of copper leaching test with sulphuric acid and influence of different process parameters (solid-liquid ratio, leaching time and temperature, stirring rate and addition of oxidizing agent) was studied to get optimal process conditions. The achieved copper leaching degree was $98 \%$. Also, Copper from the solution after leaching could be valorised through EW and precious metals present in solid residue could undergo thiourea leaching [28]

Željko Kamberović et al (2011) demonstrated the techno commercial feasibility of the treatment to waste printed circuit boards concerning great environmental and economical potentials that the precious and base metal recovery can offer. Process is techno-economically feasible for amount of gold exceeding the limit value of 500ppm.In addition; presented hydrometallurgical technology will allow the production of material with purity suitable for commercial use. [29] 
Maria Paola Luda et al (2011) Showed that Physical recycling is a promising recycling method without environmental pollution and with reasonable equipment invests; low energy cost and diversified potential applications of products. However, separation between the metallic and nonmetallic fraction from waste PCBs has to be enhanced. Metal recovery could be performed by traditional pyrometallurgical approaches on metal concentrated PCB scraps fractions. Comparing with the pyrometallurgical processing, hydrometallurgical method was more exact, more predictable, and more easily controlled. New promising biological processes is under development. [18]

Johan Sohaili et al (2012) showed that large amount of nonmetallic materials in printed circuit board (PCBs) are disposed of by combustion and disposal in landfill as the main method for treating nonmetals in PCBs, but it causes secondary pollution and resource wasting. PCBs recycling process usually includes three process which is pretreatment, physical recycling, and chemical recycling and the recovered nonmetals were used to make models, construction materials and composite boards. The study shows that PCB nonmetals can be reused in profitable and environmentally friendly ways. [15]

Johan Sohaili et al (2012) Crushing and separation are then key points for improving successful further treatments. Physical recycling is a promising recycling method without environmental pollution and with reasonable equipment invests, and diversified potential applications of products. However, separation between the metallic and non-metallic fraction from waste PCBs has to be enhanced. Comparing with the pyrometallurgical processing, hydrometallurgical method is more exact, more predictable, and more easily controlled. [16]

Youssef. Chehade et al (2012) proposed an extraction process that has been sub-divided into three stages: (1) Physical separation, (2) metal recovery, and (3) waste treatment. Stage 1 involves size reduction to $1 \mathrm{~mm}$ diameter, followed by the corona electrostatic separator and the hydro-cyclone which separate metals from non-metals. Stage 2 separates individual target metals from each other by hydrometallurgical processing. This stage involves the dissolution of metals in sulphuric acid and Aqua Regia, followed by the application of EMEW electrowinning technology which results in metal purities of up to $99.99 \%$. Stage 3 includes the treatment of by-products according to environmental, health, and safety standards. [6]

Jakub Szalatkiewicz et al (2014) presented data that identifies metals and other substances found in PCB waste based on elemental and technical analysis of PCBs. PCB categorization based on gold concentration is presented, resulting in two groups: electric and electronic PCBs. Then mass of PCBs in waste of electric and electronic equipment is presented. Presents an analysis of metals values in PCBs pointing to gold, palladium and copper as the three the most valuable metals for recovery. [12]

Jadhav $U$ et al (2015) investigated the hydrometallurgical leaching process using four different leaching agents and their respective leaching time. Among the leaching reagents examined, hydrochloric acid $(\mathrm{HCl})$ showed great potential for the recovery of metals. The $\mathrm{HCl}$ took less time for the metal recovery and was thus a very effective leachant. [11]

Muammer Kaya et al (2016) provided a comprehensive review of various physical and chemical processes for electronic waste recycling, their advantages and shortfalls towards achieving a cleaner process of waste utilization with special attention towards extraction of metallic values. After size reduction, mainly physical separation/concentration processes employing gravity, electrostatic, magnetic separators, froth floatation etc., which are commonly used in mineral processing, have been critically reviewed for separation of metals and non-metals, along with useful utilizations of the nonmetallic materials. The recovery of metals from e-waste material after physical separation through pyrometallurgical, hydrometallurgical or bio-hydrometallurgical routes is also discussed along with purification and refining. Hydrometallurgical route was found to be key player in the base and precious metals recoveries from e-waste. [21]

\section{Conclusions}

Based on Literature Review the following conclusions are drawn:

1. There are precious metals and base metals present in Waste Printed Circuit Boards obtained from used Electronic Equipment.

2. These metals are harmful and hazardous to the environment making it contaminated if land filled or dumped which is usually done. 
3. Metals such as Gold, Silver, and Copper can be recovered from these PCBs employing physical and chemical processes.

4. Major two processes are used; Pyrometallurgical and Hydrometallurgical process.

5. Hydrometallurgical process is more advanced and more economical

6. Hydrometallurgical process is basically chemical leaching process using leaching agent.

7. Physical processing can be done in the initial stage to optimize the recovery.

8. Thiorurea and Aqua Regia are the most promising leaching agents used for recovery of metals.

9. The recovery of the metals varies with the leaching conditions such as leaching period, temperature, stirring rate, etc.

10. The optimum recovery method is the Electro winning Process with three stages.

11. Stage 1 involves size reduction to $1 \mathrm{~mm}$ diameter, followed by the corona electrostatic separator and the hydro-cyclone which separate metals from non-metals.

12. Stage 2 separates individual target metals from each other by hydrometallurgical processing. This stage involves the dissolution of metals in sulphuric acid and Aqua Regia, followed by the application of EMEW electro winning technology which results in metal purities of up to $99.99 \%$.

13. Stage 3 includes the treatment of by-products according to environmental, health, and safety standards.

E-waste tends to be a bigger issue in the coming years and an effective way is needed to tackle that problem. Another challenging part is selecting the recovery method. Indeed, electro winning has the potential for a self-sufficient method for the recovery. If it is commercially applied the recycling would be both profitable and economical which would also be according to the norms and standards of environment, health and safety.

\section{ACKNOWLEDGMent}

The Authors thankfully acknowledge to Dr. C. L. Patel, Chairman, Charutar Vidya Mandal, Er. V. M. Patel, Hon. Jt. Secretary, Charutar Vidya Mandal, Prof. (Dr.) Indrajit Patel, Principal, B.V.M. Engineering College, Dr.Anand Metre, Assistant Professor, Chemical Engineering Department, GCET College, Vallabh Vidyanagar, Gujarat, India for their motivations and infrastructural support to carry out this research.

\section{REFERENCES}

[1] Balakrishnan Ramesh Babu, Anand Kuber Parande and Chiya Ahmed Basha, "Electrical and electronic waste: a global environmental problem", Waste Management Research; 25; 307, 2007

[2] Boswell HOBI International Inc. USA a Feedback Strategy for a Closed Loop EOL Cycle Process Concept, clean Electronics Products and Technology 9-11, Oct. 1995, Conference Publication 1995 IEEE.

[3] Brett H. Robinson, "E-waste: An assessment of global production and environmental impacts", Department of Soil and Physical Sciences, Lincoln University, Lincoln 7647, Canterbury, New Zealand, 2009

[4] Central Pollution Control Board (CPCB) As approved vide MoEF letter No.23-23/2007- HSMD dt. March 12, 2008. Guidelines for Environmentally Sound Management Of E- Waste by Ministry of Environment \& Forests (MoEF),

[5] Chandra. 1, 2004 and M.I. Jeffrey, an Electrochemical study of the effect of Additives and electrolyte on the dissolution of gold in Thiosulphate Solutions, Hydrometallurgy 73(2004)305312.

[6] Chehade Youssef, A.Siddique, H.Alayan, N.Sadasivam, S.Nusri and T.Ibrahim. "Recovery of Gold, Silver, Palladium, and Copper from Waste Printed Circuit Boards." International Conference on Chemical, Civil and Environmental Engineering (ICCEE'2012) March24-25, 2012.Dubai. Planetary Scientific Research Center.

[7] Chi Jung Oh 2003, Sung Oh Lee, Tae Jun Ha, and Myong Jun Kim, Selective Leaching of Valuable Metals from Waste Printed Circuit Boards, Korea, ISSN 1047- 3289, J. Air \& Waste Manage, Assoc. 53:897-902 
[8] Dunning, B W Jr, 1986, in the article "Precious Metals Recovery from Electronic Scrap and Solder Used in Electronics Manufacture, Precious metals recovery from Low-Grade Resources; Denver, Colorado; USA; 12Feb.1986. pp: 44-56,1986.

[9] Dwelling (1999) Characteristics and house equipment statistics" www.stat.gc.ca

[10] Hesselbach, Ohlendof J. "Disposal of Electronic Waste" (1999, 2001)

[11] Jadhav U. \& Hocheng H.," Hydrometallurgical Recovery of Metals from Large Printed Circuit Board Pieces", 2015

[12] Jakub Szałatkiewicz, "Metals Content in Printed Circuit Board Waste", Industrial Research Institute for Automation and Measurements, Aleje Jerozolimskie 202, 02-486 Warszawa, Poland, Pol. J. Environ. Stud. Vol. 23, No. 6, 2014 Jirang Cui and Forssberg, Mechanical Recycling of waste electric and electronic equipment A Review," Journal of Hazardous Waste materials B 99,243-263 (2003)

[13] Jirang Cui, Lifeng Zhang," Metallurgical recovery of metals from electronic waste: A review", Journal of Hazardous Materials 158, 2008

[14] Johan Sohaili, Shantha Kumari Muniyandi and Siti Suhaila Mohamad, "A Review on Printed Circuit Board Recycling Technology", Journal of Emerging Trends in Engineering and Applied Sciences, 2012

[15] Johan Sohaili, Shantha Kumari Muniyandi, Siti Suhaila Mohamad, "A Review on Printed Circuit Boards Waste Recycling Technologies and Reuse of Recovered Nonmetallic Materials", International Journal of Scientific \& Engineering Research, Volume 3, Issue 2, 2012

[16] MAIT Recycling from E-waste to Resources-Excerpts from UNEP -2010

[17] Maria Paola Luda, "Recycling of Printed Circuit Boards", Department of Chemistry IFM University of Turin, Italy, 2011

[18] Mathias Schleuep, Christan Hageluken, Christana E.M.Mesker Federco Magahini,Feng wang Esther Muller,Ruedunger Kuehr Clandia Mauver Guido Sonnemann " Market Potential of Innovative E-waste Recycling Technology in developing Countries" 2009

[19] Mellon and Matthews "Disposition and End-of-Life Options for Personal Computers" (1991)

[20] Muammer Kaya, "Recovery of Metals from Electronic waste by physical and chemical recycling processes", International Journal of Chemical, Molecular, Nuclear, Materials and Metallurgical Engineering, Vol. 10, No:2, 2016

[21] Niederkom and Steve Huzar Worid Gold Council 1984 17(4) 128-1Goldbulletin.org.

[22] Nokia Recycling Pays off Virtual Product Design: Case Study, Pertti Repo Mikko Kerttula, VIT Technical Research Centre Finland CeBIT 2004

[23] P. Gramatyka*, R. Nowosielski, P. Sakiewicz, "Recycling of waste electrical and electronic equipment Recycling of waste electrical and electronic equipment", Journal of Achievements in Materials and Manufacturing Engineering, Volume 20, Issues 1-2, January-Februaryl2007

[24] Ruediger Kuehr: "E-waste: not your normal trash": 26"^ April 2010

[25] Wolfarm Schamhorst, Hans-Jorg Althaus, Mischa Classen, Olivier Jolliet, Lorenz M.Hilty, 2005, The end of life treatment of second generation mobile phone networks: Strategies to reduce the environmental impact. Environmental Impact Assessment Review 25(2005) PP.540- 566.

[26] Ž.Kamberoviæ, M.Koraæ, D.Ivšiæ, V.Nikoliæ, M.Ranitoviæ, Processs election for hydrometallurgical WPCBs recycling, $4^{\text {th }}$ International Conference-Processing and Structure of Materials, Paliæ, Serbia, 2010.,Proceedings 67-72

[27] Ž.Kamberović, M.Korać, D.Ivšić, V.Nikolić, M.Ranitović, Hydrometallurgical process for extraction of metals from electronic waste-PartI, Metalurgija - Journal of Metallurgy, 15(4), 231-244, 2009

[28] Željko Kamberović, Marija Korać, Milisav Ranitović; "Hydrometallurgical Process for Extraction of Metals from Electronic Waste-Part II: Development of The Processes for the Recovery of Copper from Printed Circuit Boards (PCB)", Association of Metallurgical Engineers of Serbia, 2011

[29] Zhang Forssberg: A Review of Electronic demanufacturing Process $(1998,1999)$ 


\section{AUTHORS' BIOGRAPHY}

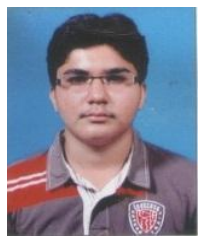

Amil Memon received his Bachelor of Engineering degree in Chemical Engineering from the Sarvajanik College of Engineering Technology (Surat), Gujarat Technological University, in 2015. At present, he is final year student of Master's Degree in Environmental Engineering from Birla Vishvakarma Mahavidyalaya, Gujarat Technological University.

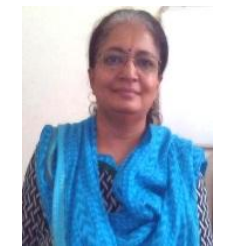

Prof. Reshma L. Patel received her Bachelor of Engineering degree in Civil Engineering from the Birla Vishvakarma Mahavidyalaya, Sardar Patel University in 1991. In 1993 she received her Master's Degree in Civil (Environmental) Engineering from Birla Vishvakarma Mahavidyalaya, Sardar Patel University. She joined Birla Vishvakarma Mahavidyalaya Engineering College as a faculty in 1994, where she is Associate Professor of Civil Engineering Department with a total experience of 22 years in the field of Research, Designing and education. She is guiding M.E. (Environmental Engineering) Thesis work in the field of Civil/ Environmental Engineering. She has published many papers in National/ International Conferences and International Journals.

Dr. Jayeshkumar R Pitroda received his bachelor of engineering degree in Civil Engineering from Birla Vishwakarma Mahavidyalaya Engineering College, Sardar Patel University in 2000. In 2009 he received his master's degree in Construction Engineering and Management form Birla Vishwakarma Mahavidyalaya Sardar Patel University. In 2015 he received his Doctor of philosophy (Ph.D.) degree in Civil Engineering from Sardar Patel University. He joined Birla Vishwakarma Mahavidyalaya Engineering College as a faculty in 2009, where he is Assistant Professor of Civil Engineering Department with a total experience of 16 years in the field of research, designing and education. He is guiding M.E. (Construction Engineering and Management) thesis work in the field of Civil / Construction Engineering. He has published many papers in National / International Conferences and International Journals. He has published seven Research Books in the field of Civil Engineering, Rural Road Construction, National Highways Construction, Utilization of Industrial Waste, Fly Ash Bricks, Construction Engineering and Management, Eco-friendly Construction. 